\title{
EFEITO DO CREEP FEEDING E CREEP GRAZING NAS CARACTERÍSTICAS DA PASTAGEM DE TIFTON E AZEVÉM E NO DESEMPENHO DE OVINOS
}

\author{
Cláudio José AraúJo da Silva ${ }^{1}$, Alda LúCIA Gomes Monteiro ${ }^{2}$, SERGio Rodrigo Fernandes ${ }^{3}$, \\ CÉSAR HENRIQUE ESPÍRITO CANDAL POLI ${ }^{4}$, ODILEI ROGÉRIO PRADO ${ }^{3}$, DAMARIS FERREIRA DE SOUZA ${ }^{5}$

\footnotetext{
${ }^{2}$ Professora Doutora da Universidade Federal do Paraná, Curitiba, PR, Brasil.

${ }^{3}$ Doutorandos da Universidade Federal do Paraná, Curitiba, PR, Brasil.

${ }^{4}$ Professor Doutor da Universidade Federal do Rio Grande do Sul, Porto Alegre, RS, Brasil

${ }^{5}$ Mestre em Ciências Veterinárias pela Universidade Federal do Paraná, Curitiba, PR, Brasil.
} \\ ${ }^{1}$ Pós-doutorando da Universidade Federal do Paraná, Curitiba, PR, Brasil. - cja001@ bol.com.br
}

\begin{abstract}
RESUMO
Objetivou-se avaliar a influência da suplementação em creep feeding e creep grazing nas características da pastagem e no desempenho e produtividade de cordeiros e ovelhas. Estudaram-se três sistemas de terminação em pastagem de Tifton-85 (Cynodon spp.) quando sobressemeada com azevém anual (Lolium multiflorum Lam.): cordeiros terminados ao pé da mãe sem suplementação (1); cordeiros terminados ao pé da mãe com suplementação concentrada a $2 \%$ do PV/dia em creep feeding (2); e cordeiros terminados ao pé da mãe com suplementação de trevo branco (Trifolium repens) ad libitum em creep grazing (3). As características da pastagem não diferiram $(\mathrm{P}>0,05)$ entre os sistemas

estudados. Os desempenhos dos cordeiros em creep feeding (307g/animal/dia) e creep grazing (274g/animal/dia) foram superiores $(\mathrm{P}<0,05)$ ao dos cordeiros não suplementados (204g/animal/dia). A produção de cordeiros por área nos sistemas com suplementação $(2,4 \mathrm{~kg}$ de $\mathrm{PV} / \mathrm{ha} / \mathrm{dia})$ foi superior $(\mathrm{P}<0,05)$ ao sistema sem suplementação $(1,8 \mathrm{~kg}$ de $\mathrm{PV} / \mathrm{ha} / \mathrm{dia})$. O trevo branco, como forrageira suplementar, consistiu em boa alternativa para terminação de cordeiros. Pode-se concluir que os sistemas de alimentação de cordeiros em creep feeding e creep grazing rendeu produtividade favorável, principalmente se há déficit de forragem na primavera.
\end{abstract}

PALAVRAS-CHAVE: cordeiros; sistemas de produção; suplementação; Tifton-85; trevo branco.

\section{EFFECT OF CREEP FEEDING AND CREEP GRAZING ON THE CHARACTERISTICS \\ OF TIFTON AND ITALIAN RYEGRASS PASTURES AND ON SHEEP PERFORMANCE}

\section{ABSTRACT}

The objective of this study was to evaluate the influence of creep feeding and creep grazing on the pasture characteristics and on performance and productivity of sheep. Three systems of lambs production on Tifton 85 (Cynodon spp.) pastures oversown with Italian ryegrass (Lolium multiflorum Lam) were studied: lambs with dams until slaughter without supplementation (1); lambs with dams until slaughter fed concentrate in creep feeders at
$2 \%$ BW.day $^{-1}$ (2); and lambs with dams until slaughter and supplemented with white clover (Trifolium repens) in creep grazing system ad libitum (3). The characteristics of the pasture did not differ $(\mathrm{P}>0.05)$ among the systems. Individual lamb growth was higher with creep feeding (307g/day) and creep grazing (274g/day) compared to no supplemented systems $(204 \mathrm{~g} / \mathrm{day} ; \mathrm{p}<0.05)$. Animal productivity per area on supplemented treatments $(2.4 \mathrm{~kg}$ 
$\mathrm{BW} / \mathrm{ha}$ /day) was significantly greater than no supplemented one $(1.8 \mathrm{~kg} \mathrm{BW} / \mathrm{ha} /$ day; $\mathrm{p}<0.05)$. White clover showed to be a particularly good supplement for raising lambs on pastures. It may be concluded that systems of feeding lambs in creep feeding and creep grazing yielded favorable productivity mainly if there is forage deficit in spring.

KEYWORDS: lambs; production systems; supplementation; Tifton-85; white clover.

\section{INTRODUÇÃO}

O desempenho de ovinos em pastagens tem sido estudado na região Sul do país, onde forrageiras anuais de inverno e perenes de verão podem ser utilizadas, permitindo adequada produção forrageira com baixo custo durante todo o ano (TONETTO et al., 2004). TODARO et al.(2004) mostraram também que os sistemas de produção em pastagens permitem obter carnes com menor conteúdo de gordura intramuscular e colesterol, melhor relação entre os ácidos graxos ômega-6:ômega-3 e maior concentração de CLA (ácido linoleico conjugado), características benéficas à saúde humana.

Os estudos de sistemas de produção de ovinos em pastagens conduzidos no Laboratório de Produção e Pesquisa em Ovinos e Caprinos (LAPOC) no Paraná, entre os anos de 2003 e 2005, demonstraram haver importante interação entre os cordeiros e suas mães. Os dados publicados por POLI et al. (2008) e RIBEIRO et al. (2009a e 2009b) indicaram que cordeiros mantidos com suas mães em pastagens, com ou sem suplementação em cochos privativos (creep feeding), apresentaram resultados satisfatórios, inclusive quanto à condição sanitária. Assim, a presença da mãe (ovelha) exerceu papel fundamental para cordeiros terminados em pastagem.

A estratégia de suplementação exclusiva para cordeiros denominada creep feeding tem sido bastante avaliada, e pesquisas demonstraram bons resultados com ganhos que variam entre 360 e $420 \mathrm{~g} / \mathrm{dia}$, utilizando-se rações à base de feno de alfafa moído, farelo de soja, grãos secos e/ou grãos úmidos de milho (ALMEIDA JR. et al., 2004). SAMPAIO et al. (2002) relataram que o uso do creep feeding pode encurtar o tempo necessário ao acabamento dos cordeiros para o abate, além de proporcionar descanso à matriz.

Com os avanços de conhecimento nos sistemas de produção de cordeiros e diante dos bons resultados da permanência dos cordeiros com as mães até o abate, busca-se avaliar outras formas de suplementação dos cordeiros nessa fase da vida além do creep feeding, tal como o creep grazing. Esse sistema é caracterizado pelo acesso exclusivo dos cordeiros a áreas com pastagens de valor nutricional superior, tais como as leguminosas forrageiras, buscando-se melhores resultados em desempenho animal. Estudos com bovinos nos Estados Unidos (HARVEY \& BURNS, 1988) demonstraram aumento significativo no ganho de peso vivo por hectare com a utilização do creep grazing. No Uruguai, os estudos com ovinos realizados pelo Instituto de Investigação Agropecuária (INIA) observaram que o ganho de peso dos cordeiros em creep grazing foi, na maioria das vezes, superior ao sistema de creep feeding (BANCHERO \& MONTOSSI, 1995ab). MOSS et al. (2009) obtiveram desempenho superior de cordeiros em creep grazing $(263 \mathrm{~g} / \mathrm{dia} \times 211 \mathrm{~g} / \mathrm{dia}, \mathrm{p}<0,01)$ com trevo branco, quando comparados com cordeiros sem creep grazing na Nova Zelândia. Ressalta-se que estudos com creep grazing no Brasil, envolvendo a espécie ovina, são inexistentes. RODRIGUES \& CRUZ (2003), em estudos com bovinos, afirmaram que precisam ser realizadas avaliações no Brasil para verificar a viabilidade desse sistema.

Diante da positiva influência da mãe no desempenho dos cordeiros em pastagens e de novos modelos produtivos, faz-se necessário avaliar se as suplementações inclusas nesses sistemas podem influenciar na estrutura das pastagens e, consequentemente, no ganho de peso e produção de cordeiros por área. Dentro desse contexto, este trabalho foi realizado com o objetivo de avaliar os efeitos dos sistemas em creep feeding e creep grazing nas características estruturais da pastagem e no desempenho de cordeiros e ovelhas.

\section{MATERIAL E MÉTODOS}

O experimento foi realizado no Laboratório de Produção e Pesquisa em Ovinos e Caprinos (LAPOC) da Universidade Federal do Paraná (UFPR), localizado em Pinhais/PR $\left(25^{\circ} 25^{\prime} \mathrm{S}\right.$; $49^{\circ} 8^{\prime} \mathrm{W}, 930 \mathrm{~m}$ altitude), no período de setembro a dezembro de 2007. O solo é mapeado como latossolo vermelho-amarelo, de textura argilosa, com relevo suave ondulado (EMBRAPA, 1999).

$\mathrm{O}$ experimento foi estabelecido em área de 3,8 ha, dividida em 9 piquetes de 0,42 ha de pastagem de Tifton-85 (Cynodon spp.), sobressemeada em 10 de abril de 2007, por meio de plantio direto, com semente de azevém anual (Lolium multiflorum Lam.) na densidade $60 \mathrm{~kg} / \mathrm{ha}$.

A leguminosa trevo branco (Trifolium 
repens) foi utilizada como forrageira suplementar para os cordeiros, sendo estabelecida em área de 0,6 ha. O plantio ocorreu dia 10 de abril de 2007 com 6 $\mathrm{kg} / \mathrm{ha}$ de sementes. A área foi isolada com tela $\mathrm{e}$ dividida em três piquetes de 0,2 ha, referentes às repetições do tratamento com alimentação privativa de volumoso ou creep grazing. O acesso dos cordeiros foi disponibilizado por passagens de $50 \mathrm{~cm}$ de altura e 17 a $22 \mathrm{~cm}$ de largura, distribuídas ao longo da tela (BANCHERO et al., 2006).

Foram comparados três sistemas de terminação em pastagem: (1) cordeiros terminados ao pé da mãe sem suplementação; (2) cordeiros terminados ao pé da mãe com suplementação concentrada a $2 \%$ do PV/dia em creep feeding; e (3) cordeiros terminados ao pé da mãe com suplementação volumosa ad libitum em creep grazing, composto por trevo branco. $\mathrm{O}$ experimento foi finalizado quando os cordeiros atingiram $33 \mathrm{~kg}$ de peso vivo pós-jejum (sólido de 16 horas), sendo os machos abatidos e as fêmeas retiradas dos piquetes. A caracterização da pastagem de trevo é apresentada na Tabela 1.

TABELA 1 - Características da pastagem de trevo branco nos três piquetes acessórios no creep grazing

\begin{tabular}{lc}
\hline Característica & Pastagem de trevo branco \\
\hline Altura (cm) & 10,6 \\
Massa de forragem (kg de MS/ha) & $2.843,3$ \\
Massa de folhas (kg de MS/ha) & $1.767,8$ \\
Massa de material morto (kg de MS/ha) & 427,8 \\
\hline
\end{tabular}

O método de utilização da pastagem foi com sistema de pastejo contínuo, com taxa de lotação variável, mantendo-se os animais testes nos piquetes e utilizando-se animais reguladores para ajustar a lotação, de acordo com a técnica put and take. Os ajustes foram realizados a cada 14 dias com base na altura média da pastagem, mantendo-se a mesma entre 15 e $20 \mathrm{~cm}$, conforme orientações descritas por CARVALHO (2004). A altura foi medida com o sward-stick, conforme metodologia descrita por BARTHRAM (1985), sendo amostrados 60 pontos por piquete.

A massa de forragem e a taxa de acúmulo de matéria seca (MS) da pastagem foram determinadas a cada 28 dias, segundo a metodologia adaptada do triplo emparelhamento. Para a estimativa da taxa de acúmulo de MS, foram utilizadas três gaiolas de restrição ao pastejo por piquete. As amostras colhidas foram submetidas à secagem em estufa a $65^{\circ} \mathrm{C}$ até peso constante. A produção de forragem de cada período foi obtida pela multiplicação da taxa de acúmulo de MS pelo número de dias do período, de acordo com CAMPBELL (1966).

Para determinação da composição morfológica e botânica da pastagem, foram colhidas três amostras de forragem por piquete, com auxílio de um retângulo de ferro de $1,50 \mathrm{x}$ $0,20 \mathrm{~m}$. De cada amostra foram retiradas subamostras de aproximadamente $50 \mathrm{~g}$ para separação das espécies Tifton-85 e azevém anual, e posterior fracionamento em lâmina foliar, colmo com bainha e material morto.

Todas as frações foram submetidas à secagem em estufa por 48 horas a $65^{\circ} \mathrm{C}$ até peso constante, e posteriormente pesadas em balança com precisão de $0,01 \mathrm{~g}$. A massa seca dessas frações foi utilizada para cálculo da massa de forragem (MF), da massa de lâminas foliares (LF), da massa de colmos + bainhas (CB) e da massa de material morto (MM), que foram expressas em $\mathrm{kg}$ de MS/ha.

O suplemento foi composto por grãos moídos de milho e farelo de soja. As composições químicas do concentrado e das pastagens estão apresentadas na Tabela 2. A composição bromatológica da forragem foi determinada a partir de amostras colhidas a cada 28 dias por meio de simulação de pastejo (BURMS et al., 1989). As análises químicas foram realizadas no Laboratório de Nutrição Animal da UFPR para determinação dos teores de proteína bruta (PB), cálcio $(\mathrm{Ca})$ e fósforo $(\mathrm{P})$, conforme descrito por SILVA (1990), e fibra em detergente neutro (FDN) e fibra em detergente ácido (FDA), conforme proposto por VAN SOEST et al. (1991). Para estimativa dos nutrientes digestíveis totais (NDT), foram utilizadas fórmulas descritas por KEARL (1982). 
TABELA 2 - Composição química da ração concentrada da pastagem de Tifton-85 com azevém anual e do trevo branco

\begin{tabular}{lrcc}
\hline \multirow{2}{*}{ Nutriente (\%) } & Ração concentrada & \multicolumn{2}{c}{ Pastagem } \\
\cline { 3 - 4 } & & Tifton-85 + Azevém anual & Trevo branco \\
\hline MS & 88,57 & 31,54 & 19,88 \\
PB & 24,75 & 14,59 & 24,17 \\
FDA & 5,39 & 32,20 & 24,88 \\
FDN & 16,26 & 70,37 & 39,20 \\
Ca & 1,16 & 0,59 & 0,97 \\
P & 0,69 & 0,36 & 0,30 \\
NDT & 89,22 & 67,59 & 75,40 \\
\hline
\end{tabular}

A idade média inicial dos cordeiros foi de 30 dias, com peso médio de $15,5 \mathrm{~kg}$, enquanto as ovelhas pesavam $72 \mathrm{~kg}$. Os cordeiros, juntamente com suas mães, tiveram uma semana de adaptação às pastagens. O ganho médio diário individual foi determinado com base na pesagem pós-jejum (sólido de 16 horas) dos animais a cada 14 dias. O ganho de PV por área foi calculado multiplicando-se o ganho médio diário individual dos animais testes pela lotação média de animais por unidade de área (número de animais/ha), durante o período experimental. $\mathrm{O}$ número de animais por hectare foi calculado considerando-se cordeiros com $25 \mathrm{~kg}$ de PV e ovelhas com $65 \mathrm{~kg}$ de PV e foram determinados com base nos pesos médios dos animais em avaliação. A pesagem a cada 14 dias também serviu para ajustar o fornecimento da suplementação com ração concentrada para os cordeiros a $2 \%$ do PV.

O delineamento foi de blocos ao acaso com três repetições (piquetes de pastagem), em parcelas subdivididas no tempo. $\mathrm{Na}$ análise, os sistemas foram considerados como tratamento principal e os períodos (meses do ano) como subparcelas. Foram utilizadas três ovelhas mães e quatro cordeiros por repetição, totalizando 27 ovelhas e 36 cordeiros da raça Suffolk. Nesse caso, foram utilizados 18 cordeiros machos não castrados e 18 cordeiras, distribuídos uniformemente nos tratamentos, com base no peso vivo (PV) aos 30 dias de idade, sexo e tipo de parto (simples e gemelar). O experimento foi subdividido em três períodos: setembro a outubro, outubro a novembro e novembro a dezembro, para melhor caracterização da pastagem. Os resultados foram submetidos à análise de variância utilizando-se o modelo linear geral (GLM) e as médias comparadas pelo teste de Tukey a 5\% de significância. As análises foram realizadas utilizando-se o pacote estatístico SAEG (2007) versão 9.1. O modelo estatístico foi:

Yijk $=\mu+B_{i}+S_{j}+P_{k}+S_{j} * P_{k}+e_{i j k}$

$Y$ : valor observado para a variável resposta no k-ésimo tempo para o j-ésimo tratamento no i-ésimo bloco;

$\mu$ : constante inerente a todas as observações;

$\mathrm{B}_{\mathrm{i}}$ : efeito do i-ésimo bloco (repetições 1,2,3);

$\mathrm{S}_{\mathrm{j}}$ : efeito do j-ésimo tratamento (sem suplemento, creep feeding, creep grazing)

$\mathrm{P}_{\mathrm{k}}$ : efeito do k-ésimo tempo observado (períodos 1,2,3);

$\mathrm{S}_{\mathrm{j}} * \mathrm{P}_{\mathrm{k}}$ : efeito da interação entre o j-ésimo tratamento com o k-ésimo tempo;

$\mathrm{e}_{\mathrm{ijk}}$ : erro aleatório correspondente às observações do k-ésimo tempo para o iésimo bloco no j-ésimo tratamento (variação do acaso sobre as observações).

\section{RESULTADOS E DISCUSSÃO}

As características da pastagem de Tifton85 e azevém anual não diferiram $(\mathrm{P}>0,05)$ entre os sistemas estudados (Tabela 3), mas apresentaram diferenças $(\mathrm{P}<0,05)$, porém, entre períodos (Tabela 4). Esses resultados mostram que o acesso exclusivo dos cordeiros ao trevo branco ou ao concentrado, como formas de suplementação, não influenciou nenhuma das características da pastagem principal. PIAZZETTA et al. (2009), estudando o comportamento ingestivo desses animais, observaram que os cordeiros permaneceram, em 
média, 58\% do tempo de pastejo no creep grazing. Mesmo nessa condição, não houve alteração na estrutura da pastagem principal.

A massa de forragem média para os três sistemas estudados foi de $4.060 \mathrm{~kg}$ de MS/ha, com a manutenção da altura da pastagem entre 15 e $20 \mathrm{~cm}$ (Tabela 3). CARVALHO (2004) recomenda que, nas condições do Sul do Brasil, seja mantida massa de forragem de 2.500 a 3.000 $\mathrm{kg} \mathrm{MS} / \mathrm{ha}$ para animais em crescimento. Dessa forma, a pastagem encontrava-se homogênea nos três sistemas de produção, com massa de forragem dentro dos padrões pretendidos para as categorias animais utilizadas no experimento.

TABELA 3 - Médias e erro-padrão para altura, massa de forragem (MF), lâminas foliares (LF), colmo e bainha (CB), material morto (MM) e relação folha:colmo da pastagem de Tifton-85 e azevém anual nos três sistemas de produção

\begin{tabular}{lccc}
\hline \multirow{2}{*}{ Variável } & \multicolumn{3}{c}{ Sistema } \\
\cline { 2 - 4 } & Cordeiros não & Cordeiros em creep & Cordeiros em creep \\
& suplementados & $14,7 \pm 1,7$ & grazing \\
\hline Altura (cm) & $16,6 \pm 1,9$ & $3.863,4 \pm 327,4$ & $3.922,6 \pm 254,3$ \\
MF (kg de MS/ha) & $4.394,7 \pm 301,7$ & $795,0 \pm 160,3$ & $837,8 \pm 142,4$ \\
LF (kg de MS/ha) & $979,5 \pm 151,1$ & $1.223,8 \pm 153,1$ & $1.223,6 \pm 139,0$ \\
CB (kg de MS/ha) & $1.519,4 \pm 205,2$ & $1.407,4 \pm 219,3$ & $1.356,2 \pm 190,2$ \\
MM (kg de MS/ha) & $1.485,3 \pm 244,7$ & $0,71 \pm 0,12$ & $0,75 \pm 0,13$ \\
Relação folha:colmo & $0,69 \pm 0,08$ & & \\
\hline
\end{tabular}

TABELA 4 - Médias e erro-padrão para altura, massa de forragem (MF), lâminas foliares (LF), colmo e bainha (CB), material morto (MM) e relação folha:colmo da pastagem de Tifton-85 e azevém anual nos três períodos avaliados

\begin{tabular}{lccc}
\hline \multirow{2}{*}{ Variável } & \multicolumn{3}{c}{ Período } \\
\cline { 2 - 4 } & Setembro-outubro & Outubro-novembro & Novembro-dezembro \\
\hline Altura (cm) & $21,1 \pm 1,5 \mathrm{a}$ & $11,3 \pm 0,4 \mathrm{~b}$ & $14,8 \pm 0,6 \mathrm{~b}$ \\
MF (kg de MS/ha) & $3.632,8 \pm 131,3 \mathrm{~b}$ & $3.616,3 \pm 243,3 \mathrm{~b}$ & $4.931,6 \pm 255,5 \mathrm{a}$ \\
LF (kg de MS/ha) & $505,8 \pm 48,9 \mathrm{~b}$ & $696,7 \pm 61,1 \mathrm{~b}$ & $1.409,8 \pm 90,9 \mathrm{a}$ \\
CB (kg de MS/ha) & $1.635,0 \pm 91,6 \mathrm{a}$ & $780,5 \pm 63,0 \mathrm{~b}$ & $1.551,2 \pm 155,8 \mathrm{a}$ \\
MM (kg de MS/ha) & $657,4 \pm 27,9 \mathrm{~b}$ & $1.931,4 \pm 147,8 \mathrm{a}$ & $1.660,1 \pm 99,8 \mathrm{a}$ \\
Relação folha:colmo & $0,30 \pm 0,02 \mathrm{~b}$ & $0,90 \pm 0,05 \mathrm{a}$ & $0,94 \pm 0,05 \mathrm{a}$ \\
\hline
\end{tabular}

Letras minúsculas diferentes na mesma linha diferem $(\mathrm{P}<0,05)$ pelo teste de Tukey.

A Figura 1 representa a dinâmica de crescimento das espécies Tifton-85 e azevémanual na primavera. $\mathrm{O}$ azevém anual estava em final de ciclo vegetativo quando iniciado $o$ experimento, com relação folha:colmo igual a 0,30. Essa condição foi acelerada pelas elevadas temperaturas (média de $18^{\circ} \mathrm{C}$ no período) associadas à baixa precipitação pluviométrica nos meses de junho $(1 \mathrm{~mm})$, julho $(122 \mathrm{~mm})$ e agosto $(13 \mathrm{~mm})$, médias abaixo dos dados históricos para a região (SIMEPAR, 2012). 


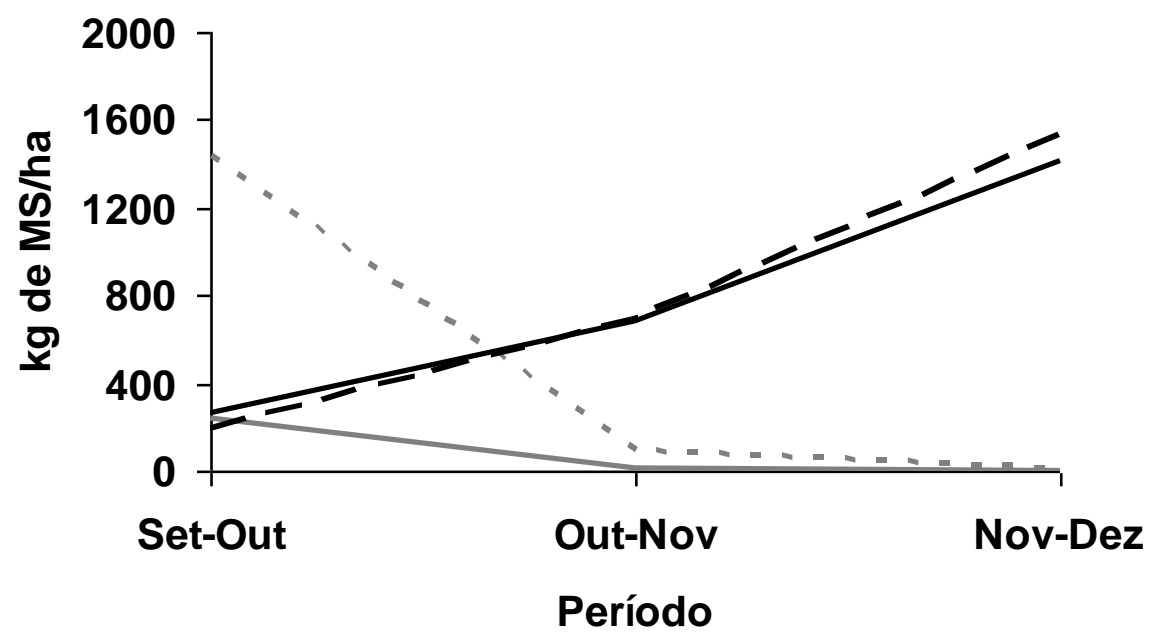

$\longrightarrow$ LFA - - - CBA - LFT - - CBT

FIGURA 1. Dinâmica de crescimento das frações lâmina foliar e colmo das espécies Tifton-85 e azevém para os três períodos avaliados.

LFA = lâmina foliar de azevém; CBA = colmo e bainha de azevém; LFT = lâmina foliar de Tifton-85; CBT = colmo e bainha de Tifton-85.

A entrada do azevém anual em estádio reprodutivo determinou a baixa quantidade de folhas nos três períodos avaliados, com média de $83,3 \mathrm{~kg}$ de MS/ha. Em setembro-outubro foi verificada maior quantidade de folhas de azevém anual $(\mathrm{P}<0,05)$ quando comparado aos demais períodos (Figura 1). A partir de outubro-novembro, houve redução na quantidade de folhas de azevém anual, de forma que em novembro-dezembro, nos piquetes com creep grazing, foi de apenas $1,2 \mathrm{~kg}$ de MS/ha, enquanto nos sistemas sem suplementação e com creep feeding as folhas inexistiram. A quantidade de colmos para o azevém foi superior à dos demais componentes da planta nos três períodos, sendo que em setembrooutubro foi observada a maior quantidade de colmos $(\mathrm{P}<0,05)$, uma vez que nessa época havia grande quantidade de inflorescência (21\% da massa de forragem) devido à fase reprodutiva, que resulta em alongamento do caule. $\mathrm{O}$ fim do ciclo do azevémanual, em conjunto com o acamamento provocado pelos animais, contribuiu para elevar a quantidade de material morto $(\mathrm{P}<0,05)$, comparada ao início do experimento (Tabela 4).

A quantidade de folhas de Tifton-85, diferentemente do azevém anual, apresentou crescimento ao longo dos períodos (Figura 1), o que implicou em aumento na massa de folhas em novembro-dezembro $\quad(\mathrm{P}<0,05) \quad($ Tabela 4$) . \quad$ A quantidade de folhas de Tifton-85 durante o período experimental foi de 787,4 kg de MS/ha, em média, o que representou $18 \%$ da massa de forragem, contribuindo para o aumento da relação folha:colmo no decorrer da primavera (Tabela 4).

A massa das frações lâmina foliar e colmo mostrou situação bastante comum para produtores da região Sul do Brasil: o vazio forrageiro da primavera (período entre setembro a novembro). Esse período foi caracterizado pelo final do ciclo das pastagens hibernais (azevém) e o início do estádio vegetativo das pastagens estivais, no caso o Tifton-85. No entanto, o período mais importante para o aproveitamento do crescimento potencial do cordeiro no Sul do Brasil é a primavera, em função da estacionalidade reprodutiva, que concentra a estação reprodutiva dos ovinos entre o verão e o outono.

A taxa de acúmulo diário de MS da pastagem principal foi diretamente influenciada pelo Tifton-85 devido ao estádio fenológico avançado do azevém anual. A taxa média de acúmulo diário de MS foi de $69,5 \pm 49,4 \mathrm{~kg} / \mathrm{ha} / \mathrm{dia}$, não sendo afetada pelos sistemas e períodos avaliados $(\mathrm{P}>0,05)$. CARNEVALLI et al. (2001) e POLI et al. (2008) observaram, respectivamente, valores de 44,5 \pm 37,3 e 115,0 $\pm 86,0 \mathrm{~kg}$ de MS/ha/dia para taxa de acúmulo diário de MS, em pastagens de Tifton-85 com ovinos. Essa variação no crescimento deve-se, 
possivelmente, às diferenças nas características do solo e das condições climáticas, como temperatura e precipitação, além da estação do ano. A massa seca acumulada foi superior $(\mathrm{P}<0,05)$ no período novembro-dezembro. A produção de forragem confirma que o Tifton-85 é boa alternativa de forragem para produção de cordeiros na região do primeiro planalto do Paraná e, possivelmente, em grande parte do Sul do Brasil, fato também observado por POLI et al. (2008).

A Tabela 5 mostra o desempenho dos animais nos sistemas de produção avaliados. O ganho de peso vivo em creep feeding e creep grazing foi maior $(\mathrm{P}<0,05)$ do que o obtido para os cordeiros não suplementados. Consequentemente, as idades de abate foram 90, 94 e 106 para os cordeiros em creep feeding, creep grazing e sem suplementação, respectivamente. Os sistemas com suplementação tiveram idade de abate significativamente $(\mathrm{P}<0,05)$ inferior, resultando em produto final proveniente de animais mais jovens. No Brasil, os pecuaristas podem ser privilegiados em pagamento, se eles comercializarem animais mais pesados com menor idade, devido à melhor qualidade da carne. Além disso, custos mais baixos nos ciclos de produção rápida de cordeiro podem ser observados devido à menor quantidade de alimentação utilizada (BARROS et al., 2009).

TABELA 5 - Médias e erro-padrão para carga animal (CA), lotação, variação do peso corporal individual (VPC) e variação do peso por área de pastagem (VPA) de cordeiros e ovelhas nos três sistemas avaliados

\begin{tabular}{lccc}
\hline & \multicolumn{3}{c}{ Sistema } \\
\cline { 2 - 4 } Variável & Cordeiros não & Cordeiros em creep & Cordeiros em creep \\
& suplementados & feeding & grazing \\
\hline Cordeiros & & & \\
CA (kg de PV/ha) & $212,6 \pm 4,6$ & $192,9 \pm 10,2$ & $209,3 \pm 16,0$ \\
Lotação (cordeiros/ha) & $8,7 \pm 0,2$ & $7,9 \pm 0,4$ & $8,6 \pm 0,7$ \\
VPC (g/animal/dia) & $204,1 \pm 12,2 \mathrm{~b}$ & $307,5 \pm 14,5 \mathrm{a}$ & $273,7 \pm 12,6 \mathrm{a}$ \\
VPA (kg de PV/ha/dia) & $1,8 \pm 0,1 \mathrm{~b}$ & $2,4 \pm 0,2 \mathrm{a}$ & $2,4 \pm 0,2 \mathrm{a}$ \\
\hline Ovelhas & & & \\
CA (kg de PV/ha) & $492,3 \pm 45,5$ & $408,1 \pm 21,0$ & $456,3 \pm 32,3$ \\
Lotação (ovelhas/ha) & $7,3 \pm 0,6$ & $6,0 \pm 0,4$ & $6,8 \pm 0,5$ \\
VPC (g/animal/dia) & $-49,6 \pm 13,6$ & $-42,1 \pm 8,9$ & $-82,1 \pm 5,0$ \\
VPA (kg de PV/ha/dia) & $-0,5 \pm 0,2$ & $-0,4 \pm 0,1$ & $-0,7 \pm 0,1$ \\
\hline CA Total (kg de PV/ha) & $704,9 \pm 49,8$ & $601,1 \pm 22,8$ & $665,6 \pm 40,2$ \\
\hline
\end{tabular}

Letras minúsculas diferentes na mesma linha diferem $(\mathrm{P}<0,05)$ pelo teste de Tukey.

Os resultados de desempenho individual mostraram que os cordeiros suplementados dependeram menos das mães para se alimentar, provavelmente por ingerirem uma menor quantidade de leite. FERREIRA (2009), ao avaliar a produção de leite das ovelhas (mães) do presente trabalho, por meio de ordenha semanal, observou que as mães dos cordeiros suplementados em creep feeding e creep grazing produziram maior volume de leite na ordenha do que as mães dos cordeiros sem suplementação. Por outro lado, os cordeiros sem suplementação e submetidos à estrutura e qualidade das pastagens inferiores (Tabelas 2 e 3 ) estariam obrigados a realizar maior consumo dessa forragem junto com suas mães, implicando em competição pela forragem, o que ressalta a importância da utilização de suplementos para cordeiros lactentes em pastagem de qualidade inferior.

Por sua vez, os sistemas de produção afetaram o ganho de peso e a produção de cordeiros por área $(\mathrm{P}<0,05)$, como mostra a Tabela 5. O sistema com creep grazing, com uma forragem de melhor qualidade, pode ser interessante para a terminação de cordeiros a pasto. BANCHERO et al. (2006) compararam sistemas com creep feeding e com creep grazing, observando menores custos com a terminação neste último, o que indicou maiores possibilidades de aplicação da técnica do creep grazing como sistema de terminação para as propriedades. As demais variáveis referentes à produtividade animal não foram afetadas $(\mathrm{P}>0,05)$ pelos sistemas, mas variaram entre os períodos. Essas variações entre períodos eram esperadas 
devido a mudanças na estrutura da pastagem, assim como na massa de forragem $(3.633$ a $4.932 \mathrm{~kg}$ de MS.ha $\left.^{-1}\right)$ e na relação folha:colmo $(0,30$ a 0,94$)$, ocorridas durante o período experimental.

O creep grazing, com forragem de melhor qualidade, mostrou-se excelente opção como fonte de nutrientes aos cordeiros, reduzindo os efeitos sazonais de variações da pastagem ofertada e o prejuízo ao desempenho animal e ao produtor. Assim, como neste trabalho, BANCHERO et al. (2006) compararam sistemas com creep feeding e com creep grazing e obtiveram ganhos individuais de $200 \mathrm{~g} /$ dia e menores custos com a terminação no creep grazing, o que indica que esse sistema pode ser utilizado na produção de cordeiros. $\mathrm{O}$ bom desempenho dos cordeiros no creep grazing, com média próxima de $274 \mathrm{~g} / \mathrm{animal} / \mathrm{dia}$, foi semelhante ao obtido por MOSS et al. (2009) na Nova Zelândia (263 g/dia), sendo, provavelmente, influenciado pela boa quantidade e qualidade do trevo branco durante o período de crescimento dos cordeiros, que apresentou massa média de forragem superior a $2.500 \mathrm{~kg}$ de $\mathrm{MS} / \mathrm{ha}$ (Tabela 1), com qualidade superior à pastagem principal (Tabela 2).

As ovelhas perderam peso durante o período experimental ( $-58 \mathrm{~g} /$ dia em média), sendo a perda mais acentuada $(\mathrm{P}<0,05)$ observada em setembrooutubro (-234 g/dia). No final da primavera, as ovelhas apresentaram ganho de 70,9 g/dia, quando a pastagem de Tifton-85 recuperou a massa de folhas do dossel (Figura 1). No início do experimento, quando a quantidade de folhas na pastagem estava bem limitada, as ovelhas encontravam-se no pico da lactação (quatro semanas pós-parto), o que provoca alta demanda nutricional, principalmente em raças de grande porte como a Suffolk (BENCINI \& PULINA, 1997). No entanto, a perda de peso de ovelhas pósparto nem sempre ocorre. Outros autores (FRESCURA et al., 2005; RIBEIRO et al., 2009a) encontraram ganhos entre 26 e $80 \mathrm{~g} / \mathrm{dia}$ em sistemas semelhantes, só que em pastagem de azevém de melhor qualidade. Essas informações indicam que a qualidade da pastagem foi determinante para o desempenho animal.

A quantidade de animais por área não foi influenciada pelas suplementações (Tabela 5). Isso demonstra que a presença do cordeiro, que apresenta menor consumo de pasto que a ovelha, não foi suficiente para influenciar a lotação, já que as suplementações propostas modificaram exclusivamente a alimentação dos cordeiros e não a das ovelhas. Os resultados de lotação e desempenho por área, obtidos para os cordeiros, foram semelhantes aos de RIBEIRO et al. (2009b), que encontraram lotações de 8,4 e 8,8 cordeiros/ha e ganhos por área de 2,2 e $2,5 \mathrm{~kg} / \mathrm{ha} / \mathrm{dia}$ em sistemas sem suplementação e com creep feeding, em pastagem de azevém, respectivamente.

A carga animal total (ovelha + cordeiros) não diferiu $(p>0,05)$ entre os sistemas, apresentando média de $657 \mathrm{~kg}$ de PC/ha, valor próximo aos $781 \mathrm{~kg}$ de PC observado por RIBEIRO et al. (2009b), que trabalharam com pastagens de azevém com relação folha:colmo média de 1,20.

Embora a massa de forragem e a altura média da pastagem do presente estudo estejam dentro do recomendado por CARVALHO (2004), a composição morfológica da pastagem mostrou que os animais tiveram acesso à forragem de limitada qualidade, o que foi confirmado pela reduzida massa média de lâminas foliares (871 kg de MS/ha), considerando que a massa de lâminas foliares deve ser mantida em $1.000 \mathrm{~kg}$ de MS/ha para que não haja limitação ao consumo (RATTRAY et al., 1987).

\section{CONCLUSÕES}

O uso do creep feeding e do creep grazing para alimentação de cordeiros não desmamados é uma importante ferramenta para sistemas de produção a pasto durante o período de deficiência de forragem, entre os períodos da pastagem de verão e a pastagem de inverno em região subtropical.

A forrageira trevo branco consistiu uma importante alternativa como fonte de nutrientes exclusiva para cordeiros, quando utilizada como suplementação forrageira em um sistema de produção a pasto com creep grazing em região subtropical.

\section{REFERÊNCIAS}

ALMEIDA JR., G.A.; COSTA, C.; MONTEIRO, A.L.G.; GARCIA, C.A.; MUNARI, D.P.; NERES, M.A. Desempenho, características de carcaça e resultado econômico de cordeiros criados em creep feeding com silagem de grãos úmidos de milho. Revista Brasileira de Zootecnia, v. 33, n. 4, p. 1.048-1.059, 2004.

BANCHERO, G.; MONTOSSI, F. Unidad experimental Ovinos. INIA. Serie de Actividades de Difusión, 78: 1422. Serie Técnica 78. INIA, p. 14-22, 1995a. disponível $\mathrm{em}$

http://www.inia.org.uy/online/site/identificar.php?idPub= 342.

BANCHERO, G.; MONTOSSI, F. Unidad experimental Ovinos. INIA. Serie de Actividades de Difusión, 78: 1422. Serie Técnica 78. INIA, p. 22-27, 1995b. disponível em

http://www.inia.org.uy/online/site/identificar.php?idPub= 342.

Ci. Anim. Bras., Goiânia, v.13, n.2, p. 165-174, abr./jun. 2012 
BANCHERO, G.; MONTOSSI, F.; GANZÁBAL, A. Alimentación estrategica de corderos: La experiência del INIA en la aplicación de las técnicas de alimentación preferencial de corderos en el Uruguay. Serie Técnica 156. INIA, 2006. 29 p. Disponível em http://www.inia.org.uy/online/site/identificar.php?idPub= 1240

BARROS, C.S.; MONTEIRO, A.L.G.; POLI, C.H.E.C.; FERNANDES, M.A.M.; ALMEIDA, R.; FERNANDES, S.R. Resultado econômico da produção de ovinos para carne em pasto de azevém e confinamento. Acta Scientiarum (UEM), v. 31, p. 77-85, 2009.

BARTHRAM, G. T. Experimental techniques: the HFRO sward stick. Penicuik: Hill Farming Research Organization, 1986. p. 29-30.

BENCINI, R.; PULINA, G. The quality of sheep milk: a review. Australian Journal of Experimental Agriculture, v. 37, n. 4, p. 485-504, 1997.

BURMS, J. C.; LIPPKE, H.; FISHER, D. S. The relationship of herbage mass and characteristics to animal responses in grazing experiments. In: MARTEN, G. C. (Ed.) Grazing Research: Design, Methodology and Analysis. CSSA, Madison, Wisconsin, 1989. p. 7-20.

CAMPBELL, A. G. Grazed pastures parameters: I. Pasture dry matter production and availability in a stocking rate and grazing management experiment with dairy cows. Journal of Agricultural Science, v. 67, n. 2, p. 211-216, 1966.

CARNEVALLI, R.A.; SILVA, S.C.; FAGUNDES, J.L.; SBRISSIA, A.F.; CARVALHO, C.A.B.; PINTO, L.F.M.; PEDREIRA, C.G.S. Desempenho de ovinos e respostas das pastagens de Tifton-85 (Cynodon spp.) sob lotação continua. Scientia Agrícola, v. 58, n. 1, p. 7-15, 2001.

CARVALHO, P. C. F. Manejando pastagens para ovinos. In: PEREIRA NETO, O. A.(Ed.); CARVALHO, P.C.F.; BONINO, J.; CONDORELLI, E. Práticas em ovinocultura: ferramentas para o sucesso. Porto Alegre: SENAR, 2004. p. 15-28. Disponível em: <http://www.senarrs.com.br/>. Acesso em: 24 abr. 2012.

EMBRAPA. Centro Nacional de Pesquisa de Solos. Sistema brasileiro de classificação de solos. Rio de Janeiro: Embrapa, 1999. 412 p. Disponível em: <http://www.cnps.embrapa.br/>. Acesso em: 24 abr. 2012.

FERREIRA, F. S. Sistema de produção de cordeiros ao pé da mãe e sua influência sobre a resposta produtiva das ovelhas em pastagem. Curitiba. 2009. $79 \mathrm{f}$. Dissertação (Mestrado em Ciências Veterinárias). Universidade Federal do Paraná. Disponível em: < http://dspace.c3sl.ufpr.br/dspace/bitstream/handle/1884/21 785/Fernanda\%20Sari\%20Ferreira.pdf?sequence $=1>$. Acesso em: 24 abr. 2012.

FRESCURA R.B.M.; PIRES, C.C.; ROCHA, M.G.; SILVA, J.H.S.; MÜLLER, L. Sistemas de alimentação na produção de cordeiros para abate aos $28 \mathrm{~kg}$. Revista Brasileira de Zootecnia, v. 34, n. 4, p. 1267-1277, 2005.
HARVEY, R. W.; BURNS, J. C. Creep Grazing and early weaning effects on cow and calf productivity. Journal of Animal Science v. 66, p. 1.109-1.114, 1988.

KEARL, L. C. Nutrient requeriments of ruminants in developing countries. International Feedstuff Institute. Utah State University, Logan, Utah, 1982.

MOSS, R.A.; DYNES R.A.; GOULTER C.L.; SAVILLE D.J. Forward creep grazing of lambs to increase liveweight gain and post-weaning resistance to endoparasites. New Zealand Journal of Agricultural Research. v.52, p. 399-406, 2009

PIAZZETTA, H.V.L.; MONTEIRO, A.L.G.; RIBEIRO, T.M.D.; CARVALHO, P.C.F.; DITTRICH, J.R.; SILVA, C.J.A. Comportamento ingestivo de cordeiros em terminação a pasto. Acta Scientiarum (UEM), v. 31, p. 227-234, 2009.

POLI, C.H.E.C.; MONTEIRO, A.L.G.; BARROS, C.S.; MORAES, A.; FERNANDES, M.A.M.; PIAZZETTA, H.V.L. Produção de ovinos de corte em quarto sistemas de produção. Revista Brasileira de Zootecnia, v. 37, n. 4, p. 666-673, 2008.

RATTRAY, P.V.; THOMPSON, K.F.; HAWKER, H.; SUMNER, R.M.W. Pastures for sheep production. In: NICOL, A. M. (Ed.). Livestock Feeding on Pasture. New Zealand Society of Animal Production. p. 89-104. 1987.

RIBEIRO, T.M.D.; MONTEIRO, A.L.G.; POLI, C.H.E.C.; MORAES, A.; SILVA, A.L.P.; BARROS, C.S. Características da pastagem de azevém e a produtividade de cordeiros em pastejo. Revista Brasileira de Zootecnia, v. 38, n. 3, p. 580-587, 2009b.

RIBEIRO, T.M.D; MONTEIRO, A.L.G.; PRADO, O.R.; NATEL, A.S.; SALGADO, J.A.; PIAZZETTA, H.V.L.; FERNANDES, S.R.. Desempenho animal e características das carcaças de cordeiros em quatro sistemas de produção. Revista Brasileira de Saúde e Produção Animal, v. 10, n. 2, p. 366-378, 2009a.

RODRIGUES, A. A.; CRUZ, G. M. Comportamento social dos bovinos e o uso do espaço. jul. 2003. Disponível em:

http://sistemasdeproducao.cnptia.embrapa.br/FontesHTM L/BovinoCorte/BovinoCorteRegiaoSudeste/alimentacao.h tm>. Acesso em: 30 ago. 2011.

SAEG. Sistema para Análises Estatísticas e Genéticas, versão 9.1: Fundação Arthur Bernardes - UFV - Viçosa, 2007.

SAMPAIO, A.A.M.; BRITO, R.M.; CRUZ, G.M.; ALENCAR, M.M.; BARBOSA, P.F.; BARBOSA, R.T. Utilização de $\mathrm{NaCl}$ no suplemento como alternativa para viabilizar o sistema de alimentação de bezerros em creepfeeding. Revista Brasileira de Zootecnia, v. 31, n. 1, p. 164-172, 2002.

SILVA, D. J. Análise de alimentos: métodos químicos e biológicos. Viçosa, MG: Universidade Federal de Viçosa, 1990. $165 \mathrm{p}$. 
SIMEPAR, Sistema Meteorológico do Paraná. Disponível em http://www.simepar.br, acesso em maio 2012.

TODARO, M.; CORRAO, A.; ALICATA, M.L.; SCHINELLI, R.; GIACCONE, P.; PRIOLO, A. Effects of litter size and sex on meat quality traits of kid meat. Small Ruminant Research, v.54, p.191-196, 2004.

TONETTO, C.J.; PIRES, C.C.; MÜLLER, L.; ROCHA, M.G.; SILVA, J.H.S.; NETO, D.P. Ganho de peso e características da carcaça de cordeiros terminados em pastagem natural suplementada, pastagem cultivada de azevém (Lolium multiflorum Lam.) e confinamento. Revista Brasileira de Zootecnia, v. 33, n. 1, p. 225-233, 2004.

VAN SOEST, P. J.; ROBERTSON, J. B.; LEWIS, B. A. Methods for dietary fiber, and no starch polysaccharides in relation animal nutrition. Journal of Dairy Science, v. 74, n. 10, p. 3.583-3.587, 1991.

Protocolado em: 01 fev. 2010. Aceito em 10 abr. 2012. 